\title{
25-Methoxyl-Dammarane-3 $\beta$, 12 , , 20-Triol, A Ginseng Saponin Derivative and an Anticancer Agent: In Vitro and In Vivo Activities, Molecular Mechanism of Action, Pharmacokinetics and Structural Modification
}

\author{
Shao Wu ${ }^{1}$, Meng Ding ${ }^{1}$, Xude Wang ${ }^{1}$, Wei $\mathrm{Li}^{1^{*}}$ and Yuqing Zhao ${ }^{1,2^{\star}}$ \\ ${ }^{1}$ School of Functional Food and Wine, Shenyang Pharmaceutical University, Shenyang 110016, China \\ ${ }^{2}$ Key Laboratory of Structure-based Drug Design and Discovery of Ministry of Education, Shenyang Pharmaceutical University, Shenyang 110016, China
}

\begin{abstract}
25-Methoxyl-dammarane-3 $\beta, 12 \beta, 20$-triol (25- $\left.\mathrm{OCH}_{3}-\mathrm{PPD}\right)$, a dammarane-type triterpene sapogenin isolated from Panax notoginseng, has shown strong antitumor effects in various human cancer cell lines, including prostate cancer, lung cancer, breast cancer, gastric cancer, colorectal cancer, pancreatic cancer, and hepatic fibrosis. This review focuses on the progress of research into $25-\mathrm{OCH}_{3}-\mathrm{PPD}$ and its derivatives in cancer therapy, including in vitro and in vivo activities, structure-activity relationships, and the molecular mechanisms of action. In addition, we also summarized a method to evaluate the oral subchronic toxicity, improve oral bioavailability, and establish quality control standards for 25- $\mathrm{OCH}_{3}$-PPD. In this review, we have provided a detailed discussion of 25-OCH $-\mathrm{PPD}$ and supplied a scientific reference for the research and development of $25-\mathrm{OCH}_{3}-\mathrm{PPD}$ as a potential anticancer drug.
\end{abstract}

Keywords: $25-\mathrm{OCH}_{3}$-PPD; Anticancer activities; Structure-activity relationships; Molecular mechanisms; Pharmacokinetics

\section{Introduction}

Traditional Chinese Medicine (TCM) has been used in cancer therapies for a long history, resulting in fewer side effects compared with chemotherapy and radiation therapy. At present, approximately three-quarters of cancer clinical trials in progress in China are a combination of TCM therapy and traditional cancer treatment $[1,2]$. The major bioactive constituents with this important herbal activity are ginsenosides, which comprise mainly of dammarane-type saponin derivatives [3,4]. A large number dammarane-type triterpene glycosides has been isolated from the roots, leaves, stems, seeds, and berries of Panax notoginseng. Dammarane-type triterpenes have been classified into protopanaxadiols (PPDs) and protopanaxatriols (PPTs) [5,6]. Furthermore, structure-activity relationships have shown that the activities of PPDs were greater than those of PPTs. Aglycones have stronger activity compared with saponins and the presence of the sugar moieties reduces compound activity, in the order: monosaccharide glycoside $>$ disaccharide glycoside $>$ trisaccharide glycoside $>$ tetrasaccharide glycoside [7-9].

A novel compound, 25-methoxyl-dammarane-3 $\beta, 12 \beta, 20$-triol (25- $\left.\mathrm{OCH}_{3}-\mathrm{PPD}\right)$ (Figure 1), a tri-tetracyclic terpene dammarane aglycone of the protopanaxadiol-type, has potent anticancer activity [10]. It can inhibit the growth and proliferation of tumor cells and induce the differentiation and apoptosis of cancer cells. The cytotoxic effects of $25-\mathrm{OCH}_{3}-\mathrm{PPD}$ have been reported in several human cancer cell lines, such as human prostate cancer, pancreatic cancer, lung cancer, gastric cancer, colorectal cancer, and breast cancer cells [11-17]. Of all known ginsenosides tested, $25-\mathrm{OCH}_{3}$-PPD showed the most potent cytotoxic effects on cancer cells. In comparison with $\mathrm{Rg}_{3}$, a clinically used anticancer treatment in China, the half-maximal inhibitory concentration $\left(\mathrm{IC}_{50}\right)$ demonstrated 10 - to 100 -fold stronger cytotoxicity in most cancer cell lines [10]. Numerous studies have shown that the anticancer activity of ginsenosides is related to the number of sugars associated with the core structure and the type of glycoside $[18,19]$. Additional studies have shown that a greater number of sugar moieties led to a gradual reduction in the anticancer effect. In order to further study and make use of the active ingredient, the chemical properties, antitumor activity, structure-activity relationship, and molecular mechanisms of action of $25-\mathrm{OCH}_{3}-\mathrm{PPD}$ and its derivatives were reviewed in this paper.

\section{Research Progress of 25- $\mathrm{OCH}_{3}$-PPD \\ Chemical and biological studies of $25-\mathrm{OCH}_{3}-\mathrm{PPD}$}

A novel compound, 20(S)-25-methoxyl-dammarane-3 $\beta, 12 \beta, 20$ triol $\left(20(\mathrm{~S})-25-\mathrm{OCH}_{3}-\mathrm{PPD}\right)$, was isolated from the total hydrolyzed saponins extracted from the leaves of $P$. notoginseng using conventional and reversed-phase silica gel chromatography. The identification of 20 (S)-25- $\mathrm{OCH}_{3}$-PPD was based on the study of its physicochemical characteristics and NMR data. $20(\mathrm{~S})-25-\mathrm{OCH}_{3}-\mathrm{PPD}$, recovered in the form of white needle-shaped crystals, has a molecular formula of $\mathrm{C}_{31} \mathrm{H}_{56} \mathrm{O}_{4}$ and a molecular weight of 492 [10]. Because the C-20 of 20(S)$25-\mathrm{OCH}_{3}-\mathrm{PPD}$ is chiral carbon atom, the compound has chiral isomers. Thus, 20(R)-25-methoxyl-dammarane-3 $\beta, 12 \beta, 20$-triol (20(R)-25$\mathrm{OCH}_{3}$-PPD) was isolated from the total hydrolyzed saponins extracted from $P$. ginseng berry and elucidated by using a combination of $1 \mathrm{D}$ and $2 \mathrm{D}{ }^{1} \mathrm{H}$ and ${ }^{13} \mathrm{C}$ NMR spectra and mass spectroscopy [19].

*Corresponding authors: Yuqing Zhao, Key Laboratory of Structure-based Drug Design and Discovery of Ministry of Education, Shenyang Pharmaceutical University, Shenyang 110016, China, Tel: +862423986521; Fax: +862423986521; E-mail: zyq4885@126.com

Wei Li, School of Functional Food and Wine, Shenyang Pharmaceutical University, Shenyang 110016, China, Tel: +862423986521; Fax: +862423986521 E-mail: wei_li1981@163.com

Received March 03, 2017; Accepted March 27, 2017; Published March 30, 2017

Citation: Wu S, Ding M, Wang X, Li W, Zhao Y (2017) 25-Methoxyl-Dammarane$3 \beta, 12 \beta, 20-T r i o l$, A Ginseng Saponin Derivative and an Anticancer Agent: In Vitro and In Vivo Activities, Molecular Mechanism of Action, Pharmacokinetics and Structural Modification. Med Chem (Los Angeles) 7: 832-836. doi: 10.4172/2161-0444.1000437

Copyright: (c) 2017 Wu S, et al. This is an open-access article distributed under the terms of the Creative Commons Attribution License, which permits unrestricted use, distribution, and reproduction in any medium, provided the original author and source are credited. 
Citation: Wu S, Ding M, Wang X, Li W, Zhao Y (2017) 25-Methoxyl-Dammarane-3 $\beta$, 12 $\beta$, 20-Triol, A Ginseng Saponin Derivative and an Anticancer Agent: In Vitro and In Vivo Activities, Molecular Mechanism of Action, Pharmacokinetics and Structural Modification. Med Chem (Los Angeles) 7: 832-836. doi: 10.4172/2161-0444.1000437

The relative cytotoxicities of the compounds in Colon 205 and A549 cell lines were as follows: $20(\mathrm{R})-25-\mathrm{OCH}_{3}-\mathrm{PPD}>20(\mathrm{~S})-25-\mathrm{OCH}_{3}-$ $\mathrm{PPD}>$ epimeric mixture of $25-\mathrm{OCH}_{3}-\mathrm{PPD}$. The $\mathrm{IC}_{50}$ values of $20(\mathrm{R})$ $25-\mathrm{OCH}_{3}-\mathrm{PPD}$ for most cell lines were similar to 20 (S) $-25-\mathrm{OCH}_{3}-$ $\mathrm{PPD}$, which were 10 - to 100 -fold more cytotoxic than $\mathrm{Rg}_{3}$. However, $25-\mathrm{OCH}_{3}-\mathrm{PPD}$ often becomes an epimeric mixture, which consists of $43 \%$ 25(S)- $\mathrm{OCH}_{3}-\mathrm{PPD}$ and $35 \%$ 25(R)-OCH$-\mathrm{PPD}$. A rapid separation method of the R-epimer of $25-\mathrm{OCH}_{3}-\mathrm{PPD}$ from its epimeric mixture by crystallization-induced dynamic resolution (CIDR) was established. This method was helpful for the further study of 20 (R) $-25-\mathrm{OCH}_{3}-$ PPD and 20(S)-25- $\mathrm{OCH}_{3}$-PPD [19,20]. Furthermore, a rapid and selective UPLC-MS/MS method was invented for the simultaneous determination of the major constituent and related substances in the raw material of $25-\mathrm{OCH}_{3}$-PPD. The method was successfully applied to establish a reasonable quality control standard for the raw material of $25-\mathrm{OCH}_{3}-\mathrm{PPD}[21]$.

The anticancer effects of $25-\mathrm{OCH}_{3}-\mathrm{PPD}$ have been reported in various human cancer cell lines (Table 1), including human colorectal cancer, lung cancer, pancreatic cancer, prostate cancer, and breast cancer cells (Figure 2). The mechanism of the anticancer effect of $25-\mathrm{OCH}_{3}$ PPD occurred through the inhibition of growth and proliferation and the induction of apoptosis in the cancer cells, which led to G1 cell cycle arrest in both PC3 and LNCaP cell lines. $25-\mathrm{OCH}_{3}-\mathrm{PPD}$ was a potent therapeutic agent against both androgen-dependent and androgenindependent prostate cancer [11]. In addition, 25- $\mathrm{OCH}_{3}-\mathrm{PPD}$ also exerted potent cytotoxic activity on pancreatic and breast cancer cells, which was achieved by the inhibition of the MDM2 oncogene and associated pathways $[11,16]$. Meanwhile, 25- $\mathrm{OCH}_{3}-\mathrm{PPD}$ showed strong cytotoxicity in colon and lung cancers cells by targeting betacatenin signaling [13-14]. Further research has shown that $25-\mathrm{OCH}_{3}-$ PPD concentration-dependently inhibited the lung cancer cell viability, had no effect on normal human lung epithelial cell activity, and increased the expression of p38 and the phosphorylation of ERK. The oral administration of $25-\mathrm{OCH}_{3}-\mathrm{PPD}(10-40 \mathrm{mg} / \mathrm{kg})$ showed a dose-dependent inhibition of xenograft tumors without affecting body weight, but reduced the expression of CD34 VEGF and MMP-9 in tumor tissue [15].

In addition, a mechanistic study revealed the potent antitumor

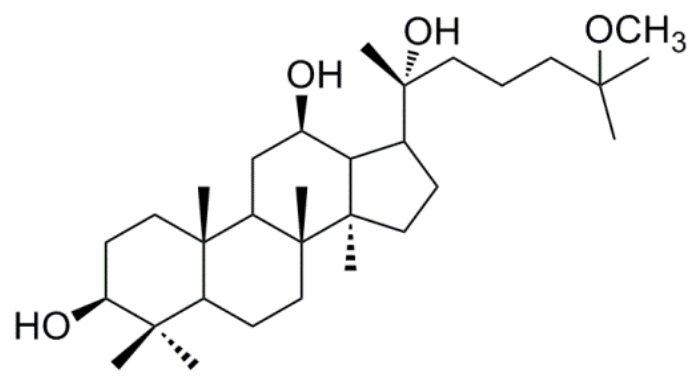

a

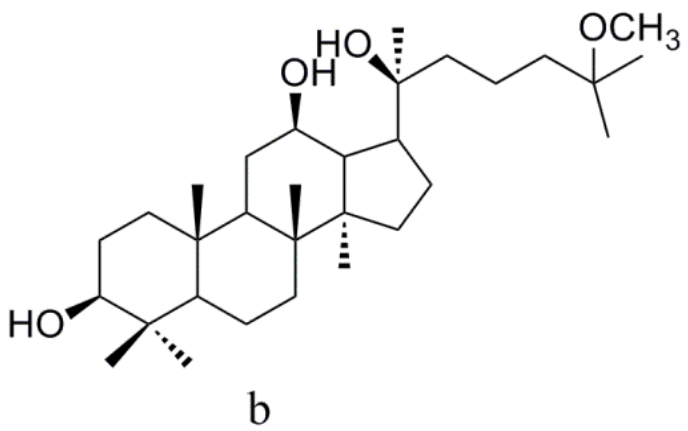

b

Figure 1: Structure of $20(\mathrm{~S})-25-\mathrm{OCH}_{3}-\mathrm{PPD}(\mathrm{a})$ and $20(\mathrm{R})-25-\mathrm{OCH}_{3}-\mathrm{PPD}$ (b).

\begin{tabular}{|c|c|c|c|c|}
\hline & \multirow{2}{*}{ Cell line } & \multicolumn{3}{|c|}{$25-\mathrm{OCH}_{3}-\mathrm{PPD}(\mu \mathrm{M})$} \\
\hline & & $\mathrm{IC}_{20}$ & $\mathrm{IC}_{50}$ & $\mathrm{IC}_{80}$ \\
\hline \multirow{4}{*}{ Prostate cancer } & LNCaP & 5.4 & 12.0 & 26.6 \\
\hline & PC3 & 1.5 & 5.6 & 20.6 \\
\hline & IMR90-EEA & 10.4 & 110.1 & $>500$ \\
\hline & IMR90-EIA & 6.2 & 275.7 & $>500$ \\
\hline \multirow{2}{*}{ Pancreas cancer } & Panc-1 & 1.2 & 7.8 & 51.6 \\
\hline & HPAC & 0.9 & 5.8 & 36.6 \\
\hline \multirow{4}{*}{ Lung cancer } & A549 & 0.66 & 4.88 & 35.86 \\
\hline & H358 & 4.48 & 19.12 & 81.7 \\
\hline & $\mathrm{H} 838$ & 3.37 & 13.39 & 53.29 \\
\hline & BEAS-2B & 4.46 & 24.61 & $>100$ \\
\hline \multirow{4}{*}{ Gastric cancer } & BGC-823 & \multirow{4}{*}{-} & 22.15 & \multirow{4}{*}{-} \\
\hline & SGC-7901 & & 32.40 & \\
\hline & MKN-28 & & 32.97 & \\
\hline & GES-1 & & 38.82 & \\
\hline Colon cancer & SW480 & - & 7.29 & - \\
\hline Breast cancer & MCF7 & - & 6.98 & - \\
\hline
\end{tabular}

Note: $I C_{20}, I C_{50}, I C_{80}$ are the concentrations that inhibit growth by 20,50 , and $80 \%$, respectively, relative to the control. "-" were not determined.

Table 1: Antiproliferative activity of $25-\mathrm{OCH}_{3}-\mathrm{PPD}$ in human tumor cells. 
Citation: Wu S, Ding M, Wang X, Li W, Zhao Y (2017) 25-Methoxyl-Dammarane-3 $\beta$, 12 $\beta$, 20-Triol, A Ginseng Saponin Derivative and an Anticancer Agent: In Vitro and In Vivo Activities, Molecular Mechanism of Action, Pharmacokinetics and Structural Modification. Med Chem (Los Angeles) 7: 832-836. doi: 10.4172/2161-0444.1000437

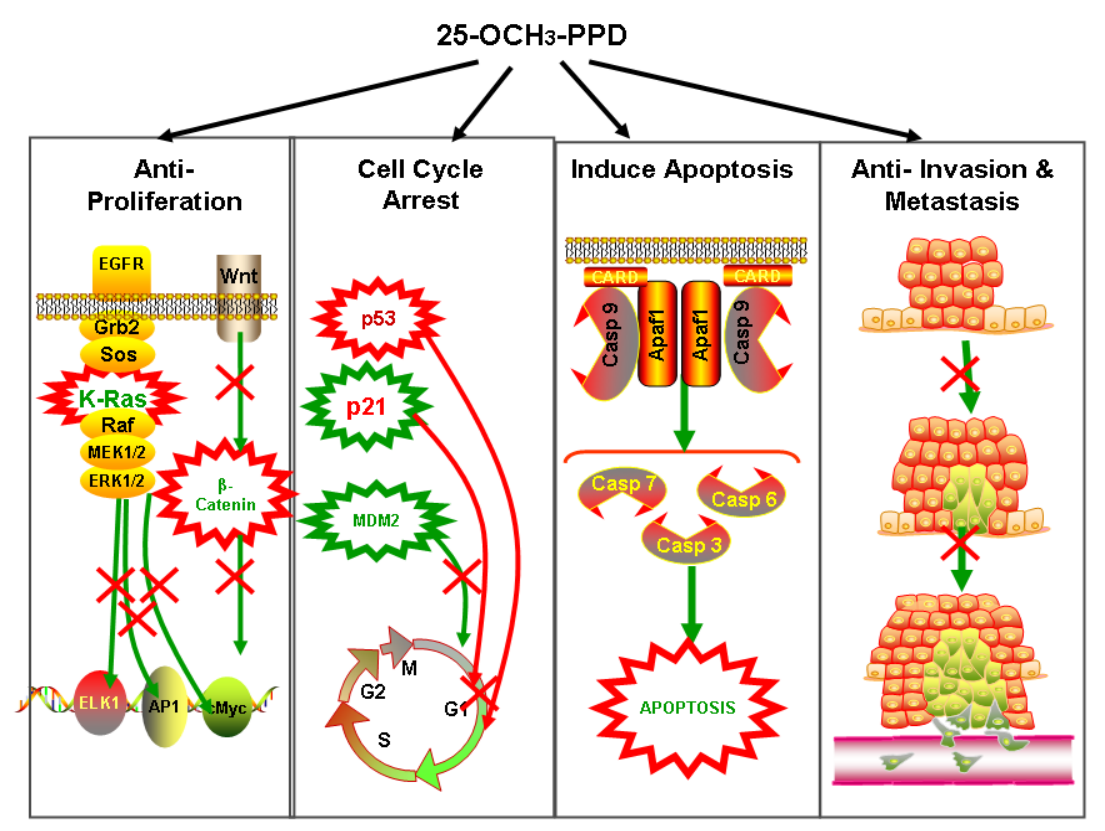

Figure 2: The anticancer molecular mechanisms of $25-\mathrm{OCH}_{3}-\mathrm{PPD}$.off.

effects of $25-\mathrm{OCH}_{3}-\mathrm{PPD}$ on gastric mucosa cells were related to the caspase signaling pathways [17]. Moreover, 25- $\mathrm{OCH}_{3}-\mathrm{PPD}$ induced the apoptosis of activated t-HSC/Cl-6 cells via c-FLIP-mediated NF$\mathrm{kB}$ activation, which suggested a potential therapeutic action against hepatic fibrosis. The dose-response subchronic toxicity study showed that no mortality and treatment-related toxicity effects resulted from the continuous oral administration of $25-\mathrm{OCH}_{3}-\mathrm{PPD}$ at any of the doses tested $(150,300$, and $600 \mathrm{mg} / \mathrm{kg})$ for 13 weeks [22].

\section{The pharmacokinetics of $25-\mathrm{OCH}_{3}-\mathrm{PPD}$}

Dammarane triterpenoids generally exhibit poor bioavailability and short half-life. The pharmacokinetics of $25-\mathrm{OCH}_{3}-\mathrm{PPD}$ epimers were studied after oral and intravenous administration in rats. The 25-O-demethylated metabolite appears as a pathway in the phase I metabolism of $25-\mathrm{OCH}_{3}-\mathrm{PPD}$ in rats; it was shown that the absolute bioavailability of $25-\mathrm{OCH}_{3}-\mathrm{PPD}$ was approximately $19.7 \%$ and the drug-time curve of 25- $\mathrm{OCH}_{3}$-PPD exhibited distinct double-peaks after oral administration. In addition, the apparent distribution volume and plasma clearance of $20(\mathrm{R})$ - and (S) $-25-\mathrm{OCH}_{3}-\mathrm{PPD}$ was significantly different $[23,24]$. The low oral bioavailability and rapid reduction of $25-\mathrm{OCH}_{3}-\mathrm{PPD}$ in the blood indicated that formulation modification was required. The relative bioavailability of a self-microemulsifying drug delivery system (SMEDDS) was dramatically enhanced by an average of 9.8-fold compared with the suspension [25]. A nanoemulsion loaded with a $25-\mathrm{OCH}_{3}-\mathrm{PPD}$ phospholipid complex was also developed. After the oral administration of the nanoemulsion and the suspension of $25-\mathrm{OCH}_{3}-\mathrm{PPD}$ in rats, peak plasma concentration and area under the curve $(0-24 \mathrm{~h})$ of the nanoemulsion of $25-\mathrm{OCH}_{3}-\mathrm{PPD}$-phospholipid complex were 3.9- and 3.5-fold higher than those of free compound [26]. Furthermore, the molecular interactions between $25-\mathrm{OCH}_{3}-\mathrm{PPD}$ and phospholipid 1,2-distearoyl-sn-glycero-3-phosphocholine (DSPC) were investigated by using the Langmuir film balance technique. The interfacial stabilization of the $25-\mathrm{OCH}_{3}-\mathrm{PPD} / \mathrm{DSPC}$ system was fairly strong owing to hydrophobic interactions and this system had the capacity to load large amounts of $25-\mathrm{OCH}_{3}-\mathrm{PPD}$ [27].

In addition, the metabolism of $25-\mathrm{OCH}_{3}$-PPD in liver microsomes of human, monkey, dog, rat, and mice was identified, and showed that $25-\mathrm{OCH}_{3}-\mathrm{PPD}$ was extensively metabolized in the aforementioned mammalian species. The catalytic oxidation and metabolism of CYP3A4 played an important role in the efficacy of $25-\mathrm{OCH}_{3}-\mathrm{PPD}$, especially in the C-20 hydroxyl group [28,29].

\section{The derivatives of $25-\mathrm{OCH}_{3}-\mathrm{PPD}$}

There have been many studies on the antitumor effect of ginsenosides, which have included structural modifications, such as esterification, alkylation, catalytic hydrogenation, and oxidation. Pharmacokinetic studies have also indicated that ginsenoside fatty acid esters might be the antiproliferative active component in vivo. Thus, at present, the structural modification of $25-\mathrm{OCH}_{3}-\mathrm{PPD}$ is mainly focused on esterification. The higher reactivity of positions 3 and 12 allows carboxylic acid to be used in $\mathrm{CH}_{2} \mathrm{Cl}_{2}$ using $\mathrm{N}, \mathrm{N}$ dicyclohexylcarbodiimide (DCC) as a condensing agent with 25- $\mathrm{OCH}_{3}-\mathrm{PPD}$ as the starting material and 4-dimethylaminopryidine (DMAP) as a catalyst for selective esterification. Meanwhile, the simple ester derivatives of $25-\mathrm{OCH}_{3}-\mathrm{PPD}, 1 \mathrm{a}, 1 \mathrm{~b}, 2 \mathrm{a}$, and $2 \mathrm{~b}$ (Figure 3 ), showed stronger antiproliferative activities than $25-\mathrm{OCH}_{3}-\mathrm{PPD}$ in the human lung cancer cell line A549, the human cervical cancer cell line HeLa, the human breast cancer line MCF-7, and the human colon cancer cell line HT-29. However, they produced no obvious effects on the human ovarian surface epithelial cells IOSE144. The results showed that the antiproliferative activity of the ester derivatives of $25-\mathrm{OCH}_{3}-\mathrm{PPD}$ decreased with an increase in the length of the fatty acid carbon chain of the substitutions. Modification with short-chain fatty acids, such as acetic acid, resulted in potent antiproliferative activity [30].

\section{Conclusion}


Citation: Wu S, Ding M, Wang X, Li W, Zhao Y (2017) 25-Methoxyl-Dammarane-3 $\beta$, 12 $\beta$, 20-Triol, A Ginseng Saponin Derivative and an Anticancer Agent: In Vitro and In Vivo Activities, Molecular Mechanism of Action, Pharmacokinetics and Structural Modification. Med Chem (Los Angeles) 7: 832-836. doi: 10.4172/2161-0444.1000437

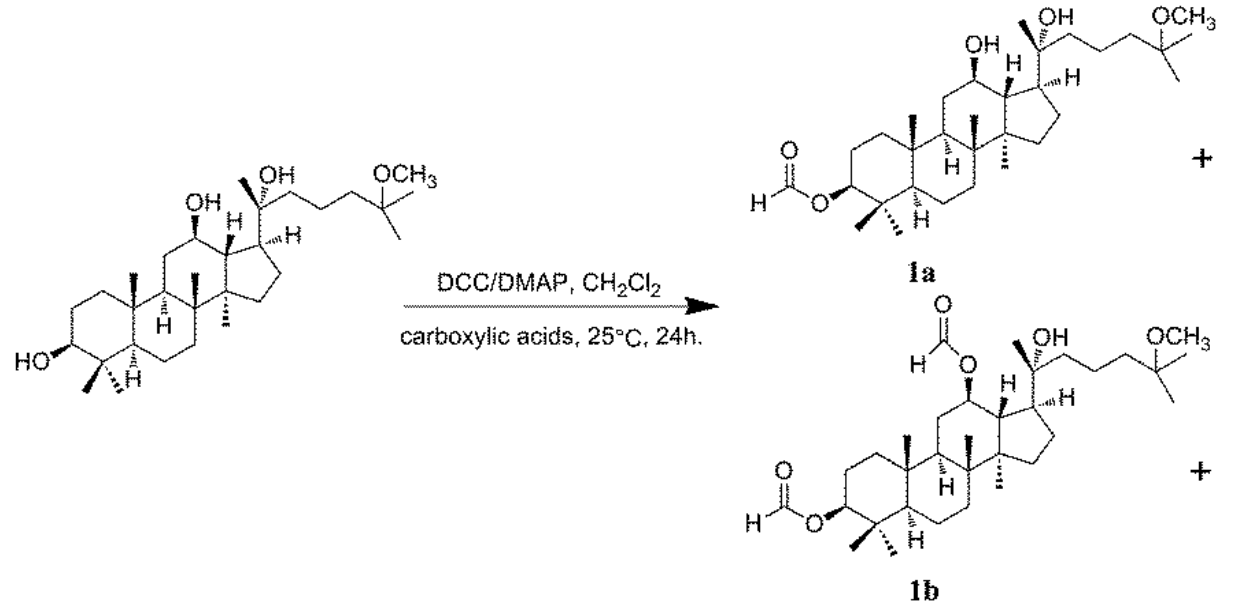

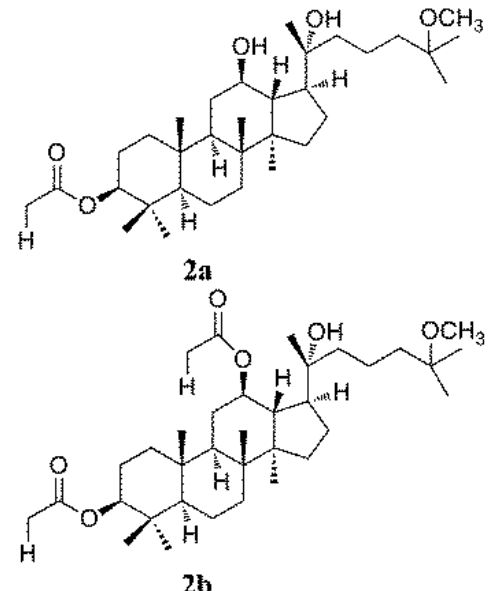

$2 \mathbf{b}$

Figure 3: The conversion of $25-\mathrm{OCH}_{3}-\mathrm{PPD}$ to the derivatives of $25-\mathrm{OCH}_{3}-\mathrm{PPD}(1 \mathrm{a}, 1 \mathrm{~b}, 2 \mathrm{a}, 2 \mathrm{~b})$.

Since the discovery of $25-\mathrm{OCH}_{3}-\mathrm{PPD}$ isolated from the total hydrolyzed saponins extracted from the leaves of $P$. notoginseng, research into its biological activity and the structure-activity relationships has produced many breakthroughs. $25-\mathrm{OCH}_{3}-\mathrm{PPD}$ has demonstrated the strong cytotoxic effects in tumor cells and relatively non-toxic effects in normal cells. The simple ester derivatives of $25-\mathrm{OCH}_{3}-\mathrm{PPD}$ showed stronger cytotoxic activity than $25-\mathrm{OCH}_{3}-\mathrm{PPD}$. This paper is the first review of the progress of the research into $25-\mathrm{OCH}_{3}-\mathrm{PPD}$ and provides a scientific reference for the design of $25-\mathrm{OCH}_{3}-\mathrm{PPD}$ as a potential anticancer agent.

However, further study of the structure-activity relationship and anticancer mechanism of these derivatives is necessary. Searches for the target of the antitumor effect of $25-\mathrm{OCH}_{3}$-PPD were helpful for the discovery of the lead compounds. Computer-aided drug simulation is an advanced technology for the optimization and design of lead compounds. Thus, the use of computer-aided drug modeling techniques for the design of improved activity, bioavailability, and lower toxicity precursor compounds was feasible for further design and study of the antitumor activity of $25-\mathrm{OCH}_{3}-\mathrm{PPD}$ derivatives. In addition, in order to screen the better lead compounds, the pharmacokinetic studies of the derivatives of $25-\mathrm{OCH}_{3}-\mathrm{PPD}$ should also be considered.

\section{Conflict of Interest}

The authors have no relevant affiliations or financial involvement with any organization or entity with a financial interest in or financial conflict with the subject matter or materials discussed in the manuscript. This includes employment, consultancies, honoraria, stock ownership or options, expert testimony, grants or patents received or pending or royalties.

\section{Acknowledgements}

This work was financially supported by the "11th Five-Year" State Plan on Technology Major Projects (2009ZX09102-114), Technology Platform of Industrialization Chromatographic Preparation for Standard Extract of Traditional Chinese Medicine (2010ZX09401-304-105B) and the National Science Foundation of China (No. 81273389).

\section{References}

1. Gao MJ, Zhao A, Zhu L, Cui XM (2012) Research and development of new food resource of Panax notoginseng. Chin Med J Res Prac 26: 34-35.

2. Guo HB, Cui XM, An N, Cai GP (2010) Sanchi ginseng (Panax notoginseng (Burkill)F.H.Chen) in China: distribution, cultivation and variations. Genet. Resour. Crop Evol 57: 453-460.
3. Li W, Fitzloff JF (2001) A validated method for quantitative determination of saponins in notoginseng (Panax notoginseng) using high-performance liquid chromatography with evaporative light-scattering detection. J Pharm Pharmacol 53: 1637-1643.

4. Chen Y, Zhan E, Chen H, Duan X, Guo L (2002) Saponins with low sugar chain from the leaves of Panax notoginseng (Burk) F. H. Chen. Zhong Yao Cai 25: 176-178.

5. Kasai R, Besso H, Tanaka O, Saruwatari Y, Fuwa T (1983) Saponins of red ginseng. Chem. Pharm. Bull 31: 2120-2125.

6. Sanada S, Kondo N, Shoji J, Tanaka O, Shibata S (1974) Studies on the saponin of ginseng. I. Structures of ginsenoside-Ro, -Rb1, -Rc, and -Rd. Chem. Pharm. Bull 22: 421-428.

7. Akao T, Kida H, Kanaoka M, Hattori M, Kobashi K (1998) Intestinal bacterial hydrolysis is required for the appearance of compound $\mathrm{K}$ in rat plasma after oral administration of ginsenoside Rb1 from Panax ginseng. J Pharm Pharmacol 50: $1155-1160$

8. Wakabayashi C, Murakami K, Hasegawa H, Murata J, Saiki I (1998) An intestinal bacterial metabolite of ginseng protopanaxadiol saponins has the ability to induce apoptosis in tumor cells. Biochem Biophys Res Commun 246 725-730.

9. Wang W, Zhao Y, Rayburn ER, Hill DL, Wang H, et al. (2007) In vitro anticancer activity and structure-activity relationships of natural products isolated from fruits of Panax ginseng. Cancer Chemother Pharmacol 59: 589-601.

10. Zhao Y, Wang W, Han L, Rayburn ER, Hil DL, et al. (2007) Isolation, structural determination, and evaluation of the biological activity of $20(\mathrm{~S})-25$-methoxyldammarane-3ß,12ß,20-triol [20(S)-25-OCH3-PPD], a novel natural product from Panax notoginseng. Med Chem 3: 51-60.

11. Wang W, Wang H, Rayburn E, Zhao Y, Hill DL, et al. (2008) 20(S)-25-methoxyldammarane-3beta,12beta,20-triol,a novel natural product for prostate cancer therapy activity in vitro and in vivo and mechanisms of action. $\mathrm{Br} \mathrm{J}$ Cancer 98 : 792-802.

12. Wang W, Rayburn ER, Zhao Y, Wang H, Zhang R (2009) Novel ginsenosides 25-OH-PPD and 25-OCH3-PPD as experimental therapy for pancreatic cancer: anticancer activity and mechanisms of action. Cancer Letters 278: 241-248.

13. Wang W, Rayburn ER, Hang J, Zhao Y, Wang H, et al. (2009) Anti-lung cancer effects of novel ginsenoside 25-OCH(3)-PPD. Lung Cancer 65: 306-311.

14. Bi X, Xia X, Mou T, Jiang B, Fan D, et al. (2014) Anti-tumor activity of three ginsenoside derivatives in lung cancer is associated with $\mathrm{Wnt} / \mathrm{ß}$-catenin signaling inhibition. Eur J Pharmacol 742: 145-152.

15. Zhang LH, Jia YL, Lin XX, Zhang HQ, Dong XW, et al. (2013) AD-1, a nove ginsenoside derivative, shows anti-lung cancer activity via activation of the $p 38$ MAPK pathway and the generation of reactive oxygen species. Biochimica et Biophysica Acta 1830: 4148-4159. 


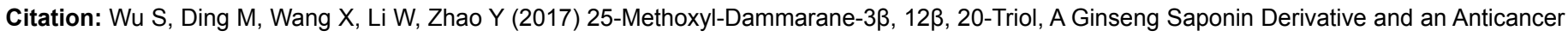
Agent: In Vitro and In Vivo Activities, Molecular Mechanism of Action, Pharmacokinetics and Structural Modification. Med Chem (Los Angeles) 7: 832-836. doi: 10.4172/2161-0444.1000437

16. Wang W, Zhang X, Qin JJ, Voruganti S, Nag SA, et al. (2012) Natural Product Ginsenoside 25-OCH3-PPD Inhibits Breast Cancer Growth and Metastasis through DownRegulating MDM2. PLoS ONE 7: e41586.

17. Zhao C, Su G, Wang X, Zhang X, Guo S, et al. (2015) Antitumor activity of ginseng sapogenins, $25-\mathrm{OH}-\mathrm{PPD}$ and $25-\mathrm{OCH} 3-\mathrm{PPD}$, on gastric cancer cells. Biotechnol Lett 38: 43-50.

18. Wang K, Zhao YQ (2008) Chemical constituents of the hydrolysate of saponins from the basal part of stem of Panax notoginseng. Chin. J. Med. Chem 18: 288-290.

19. Zhao JM, Li N, Zhang H, Wu CF, Piao HR, et al. (2011) Novel dammarane-type sapogenins from Panax ginseng berry and their biological activities. Bioorg. Med. Chem. Lett 21: 1027-1031.

20. Zhang S, Tang Y, Cao J, Zhao C, Zhao Y (2015) Crystallization-induced dynamic resolution R-epimer from 25-OCH3-PPD epimeric mixture. Journal of Chromatography B 1005: 39-46.

21. Ding M, Lu J, Zhao C, Zhang S, Zhao Y (2016) Determination of 25-OCH3PPD and the related substances by UPLC-MS/MS and their cytotoxic activity, Journal of Chromatography B 1022: 274-280.

22. Li W, Zhang X, Xin Y, Xuan Y, Liu J, et al. (2016) Oral subchronic toxicity evaluation of a novel antitumor agent 25-methoxydammarane-3ß,12ß,20-trio from Panax notoginseng in Sprague-Dawley rats. Regulatory Toxicology and Pharmacology 77: 240-251.

23. Shi $\mathrm{CH}$, Zhang X, Suo H, Yin T, Xu H, et al. (2013) Simultaneous determination by LCMS/MS of 25-methoxydammarane-3ß,12ß,20-triol epimers and active metabolites in rat plasma after intravenous administration. Xenobiotica 43: 868-874.
24. Zhang X, Xu J, Zhang D, Gu J, Zhao Y (2009) Pharmacokinetics of 20(S)-25 methoxyl-dammarane-3beta, 12beta, 20-triol and its active metabolite after oral and intravenous administration in rat. Xenobiotica 39: 457-464.

25. Sha X, Wu J, Chen Y, Fang X. (2014) Self-microemulsifying drug-delivery system for improved oral bioavailability of 20(S)-25-methoxyl-dammarane-3ß,12ß,20-triol: preparation and evaluation.International Journal of Nanomedicine 9: 913-920.

26. Zhang X, Zhang Y, Guo S, Bai F, Wu T, Zhao Y. (2016) Imporoved the oral bioavailability of 20(R)-25-methoxyl-dammarane-3ß,12ß,20-triol using nanoemulsion based on phospholipid complex: design, characterization and in vivo pharmacokinetics in rats. Drug Design, Development and Therapy 10 3707-3716.

27. Yin T, Cao X, Liu X, Wang J, Shi C, et al. (2016) Interfacial molecular interactions based on the conformation recognition between the insoluble antitumor drug AD-1 and DSPC. Colloids and Surfaces B: Biointerfaces 146: 902-909.

28. Zhang X, Zhang J, Li W, Liu L, Sun B, et al. (2014) In Vitro Metabolism of 20(R)25-Methoxyl-Dammarane-3ß,12ß,20-triol from Panax notoginseng in Human, Monkey, Dog, Rat, and Mouse Liver Microsomes. PLoS ONE 9: e94962.

29. Suo H, Zhao YQ, Shi CH, Li ZY, Liu YF, et al. (2014) Identification of metabolites of 20(R)-25-methoxyldammarane-3ß,12ß,20-triol in rats. J Shenyang Pharm Univ 31: 127-133.

30. LiuYF, YuanHN, BiXL, PiaoHR, CaoJQ, etal. (2013)25-Methoxylprotopanaxadio derivatives and their anti-proliferative activities. Steroids 78: 1305-1311. 